$1-1-1956$

\title{
Blackpatch of red clover and other legumes caused by Rhizoctonia leguminicola sp. nov.
}

Francis Jacob Gough

Edward Sumner Elliott

Follow this and additional works at: https://researchrepository.wvu.edu/ wv_agricultural_and_forestry_experiment_station_bulletins

\section{Digital Commons Citation}

Gough, Francis Jacob and Elliott, Edward Sumner, "Blackpatch of red clover and other legumes caused by Rhizoctonia leguminicola sp. nov." (1956). West Virginia Agricultural and Forestry Experiment Station Bulletins. 387T.

https://researchrepository.wvu.edu/wv_agricultural_and_forestry_experiment_station_bulletins/637 @ WVU. It has been accepted for inclusion in West Virginia Agricultural and Forestry Experiment Station Bulletins by an authorized administrator of

The Research Repository @ WVU. For more information, please contact ian.harmon@mail.wvu.edu. 

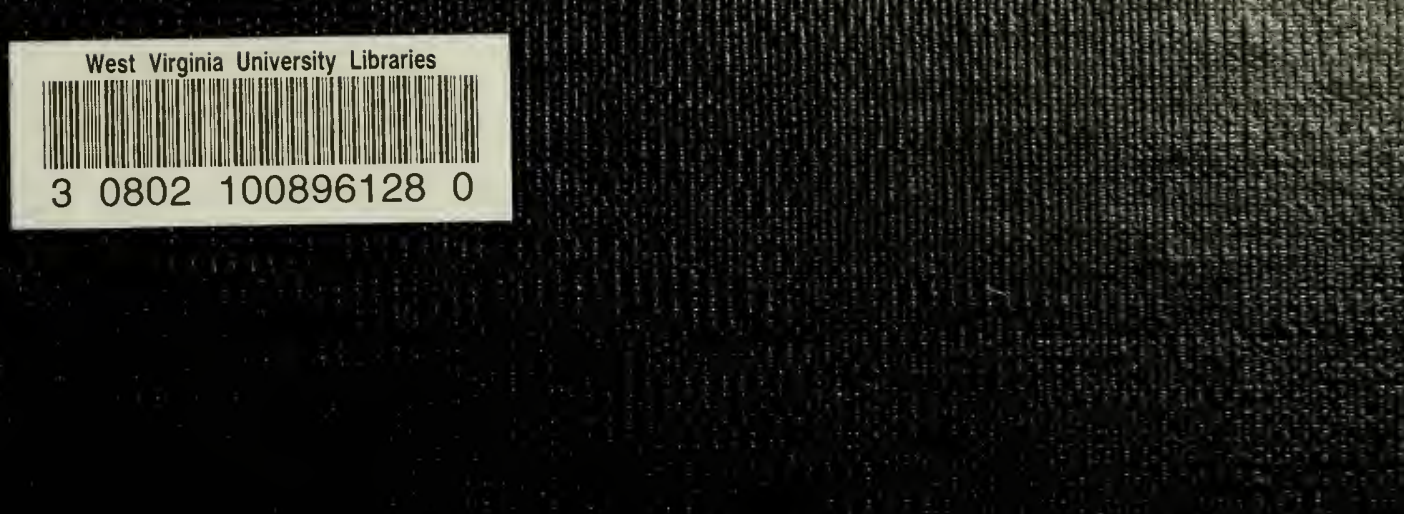
Digitized by the Internet Archive in 2010 with funding from

Lyrasis Members and Sloan Foundation 


\section{BULLETIN 387T}

January 1956

Blackpatch of Red Clover and Other Legumes Caused by Rhizoctonia leguminicola sp. nov.

WEST VIREINIA UNUERSTIY AGRLCULTURAL EXPERRMENT STATION 


\section{THE AUTHORS}

FRANCIS J. GOUGH is Assistant in Plant Pathology at the West Virginia University Agricultural Experiment Station. EDWARD S. ELLIOTT is Assistant Plant Pathologist at the West Virginia University Agricultural Experiment Station and Assistant Professor of Plant Pathology in the College of Agriculture, Forestry, and Home Economics.

WEST VIRGINIA UNIVERSITY Agricultural EXPERIMENT Station

COllege of Agriculture, Forestry, ANd HOME Economics

H. R. VARNEY, DiRECTOR MORGANTOWN 


\section{Summary}

1. Blackpatch was first reported from Kentucky in 1933. It has also been reported from Wisconsin, Georgia, Tennessee, Illinois, Delaware, and West Virginia.

2. Blackpatch has caused considerable losses during some years to the red clover seed crop in eastern West Virginia.

3. The symptoms of blackpatch on leaves are spreading, zonate lesions which may kill an entire leaf within a few hours. Individual lesions are usually connected by strands of superficial dark mycelium. Stems may show similar zonate lesions or may be encased in a web of superficial mycelium. Flower parts show necrotic lesions from which the mycelium may spread over the entire flower head. Greater damage is done to seed when the head is infected at the early stages of flowering.

4. The fungus causing blackpatch has never been observed to form spores and has remained unnamed. Under some iaboratory conditions sclerotia are formed. The name Rhizoctonia leguminicola sp. nov., is proposed for the blackpatch fungus.

5. Many factors may influence sclerotia production; nutritional factors seem to be of major importance. The production of sclerotia by $R$. leguminicola was favored when the following nitrogen sources were added to a glucose agar medium: asparagine (Difco), peptone (Difco), DL-beta-phenylalanine and potassium nitrate. No sclerotia formed when casein hydrolysate, urea, casamino acids (Difco), ammonium sulfate, ammonium tartrate or ammonium nitrate were used. Over the range of concentrations tried, 0.05 per cent asparagine induced most active production of sclerotia. Numerous sclerotia formed when the sugars D-glucose, D-mannose, D-fructose, maltose and sucrose were used as single carbon sources but few developed in media where D-galactose, $\mathrm{D}$-xylose or lactose were used. Temperatures favoring growth $\left(25^{\circ}-29^{\circ} \mathrm{C}\right.$. $)$ also favored the production of sclerotia. Sclerotia formed best at it $\mathrm{pH}$ ranging initially between 5.9 and 7.5 .

6. The blackpatch discase has been reported only on leguminous hosts. In addition to its occurrence on red clover and a number of other common hosts, it has been found in this region on black medick (Medicago lupulina L.) and Korean lespedeza (Lespedeza stipulacea Maxim). Inoculations have resulted in infections on bush beans (Phaseolus vulgaris var. humilis) under some greenhouse conditions. 
7. Although favored by high humidity, the fungus can stand prolonged severe desiccation well enough to suggest that the disease can develop in dry weather on the moisture supplied by dew.

8. The disease can be disseminated over long distances through the shipment of infected seeds. Local spread is by mycelial growth from infected seeds and by scattering of diseased plant parts. Temperature and longevity studies indicate that the fungus may winter over not only within infected seeds but in diseased plants. Probably both sources serve to provide inoculum for the following year.

9. Unsuccessful control procedures attempted so far in the field include (1) the application of foliage fungicides to the seed crop before the flowering period, (2) the application of ground sprays at about the time of renewed growth in the spring and immediately after the first cutting, and (3) seed treatments.

10. Seed treatments alone would be effective if the seed were sown in areas free of the disease. Some reduction in damping-off losses might be obtained even in reseeded fields in years when survival of the fungus on infected plant parts was low.

11. Attempts to find resistant individuals have so far failed, but the search for plants resistant to blackpatch should continue. 


\section{Blackpatch of Red Clover and Other Legumes Caused by Rhizoctonia leguminicola sp. nov.}

FRANCIS J. GOUGH and EDWARD S. ELLIOTT

\section{Introduction}

LACKPATCH, a fungus disease of clovers and other legumes, was first described in 1933 when it was reported on red and white clover in Kentucky (2). It was reported from Wisconsin in 1937 by Smith (11) who studied the development and pathological histology of the disease. Weimer (14) reported blackpatch on soybean and other legumes in Georgia.

Blackpatch was first reported in West Virginia in 1950 (5). The disease was very severe in counties of the Eastern Panhandle. In 1951 Leach and Elliott (9) reported that the fungus was carried over from year to year on a small percentage of the seed harvested from infested fields. Histological studies by Tenney (13) revealed the mycelium of the fungus inside the seed coat both between the cotyledons of the embryo and within the endosperm. Investigators working with this organism have observed that it does not produce spores; it is probably for this reason that the fungus has not been classified and named.

The purpose of this bulletin is to bring together the already known facts about the disease, to report new information concerning it, and to propose a name for the pathogenic fungus.

\section{Economic Importance}

Leach and Elliott (9) reported blackpatch to be a limiting factor in red clover seed production in West Virginia and observed that a reduction of seed yields as great as 50 per cent may occur in heavily infested fields. It was recognized that seed transmission of the organism was significant in local spread, as well as in long-range distribution. Since the organism produces no spores, the number of infection centers in the field, originating from infected seed, may largely determine the extent of local infection. The loss in forage yield due to the rapid 
invasion of the lower portions of the plant by the organism is significant. Smith (11) reported that an entire leaflet could be killed within 48 hours under optimum conditions. The amount of loss caused by this disease in other states has not been definitely established. Blackpatch is one of the major problems in clover seed production in the Eastern Panhandle of West Virginia (5).

\section{Geographic Distribution}

Blackpatch has been reported from Wisconsin, Georgia, Kentucky, and West Virginia. Verbal reports also indicate that the disease is occasionally found in Virginia, Maryland, and Pennsylvania. This is to be expected since the area in West Virginia where the disease is commonly found is within a few miles of the boundary of these states.

An attempt was made to extend the known distribution of the disease in North America by isolating the fungus from seed samples. A total of 187 lots of seed were tested from 23 states, Alaska, and 7 provinces of Canada.

One plate sample containing seed from Willow Grove, Delaware, contained the fungus mycelium. This was the only sample of all those tested in which the fungus was found.

Since the samples cannot be considered representative of an entire state or province, the negative results cannot be taken as conclusive evidence that the disease does not exist in those regions.

In addition to the states listed above, the organism has previously been isolated by J. G. Leach ${ }^{1}$ from seed grown in Tennessee and by J. W. Gerdemann² from red clover produced in Illinois.

\section{Symptoms}

The symptoms of blackpatch observed on red clover leaves are as Smith (11) described them. In the field, the symptoms most commonly observed on the leaves are dark necrotic lesions. In the early stages these may show concentric zonation (Figure 1). The pathogen advances rapidly within the host tissue, and may, at the same time, establish new points of infection wherever the aerial mycelium comes in contact with the leaf surface. Necrotic areas often coalesce to form irregular lesions. Under favorable conditions, a leaflet may be killed within a few hours. The leaves near the ground where the air is humid are generally infected first.

As pointed out in earlier work in West Virginia (6), the organism attacks the stems, flower parts, and seeds, as well as the leaves, although

1Personal communication, March 17, 1954.

$21 n$ a personal letter, dated December 1, 1953 


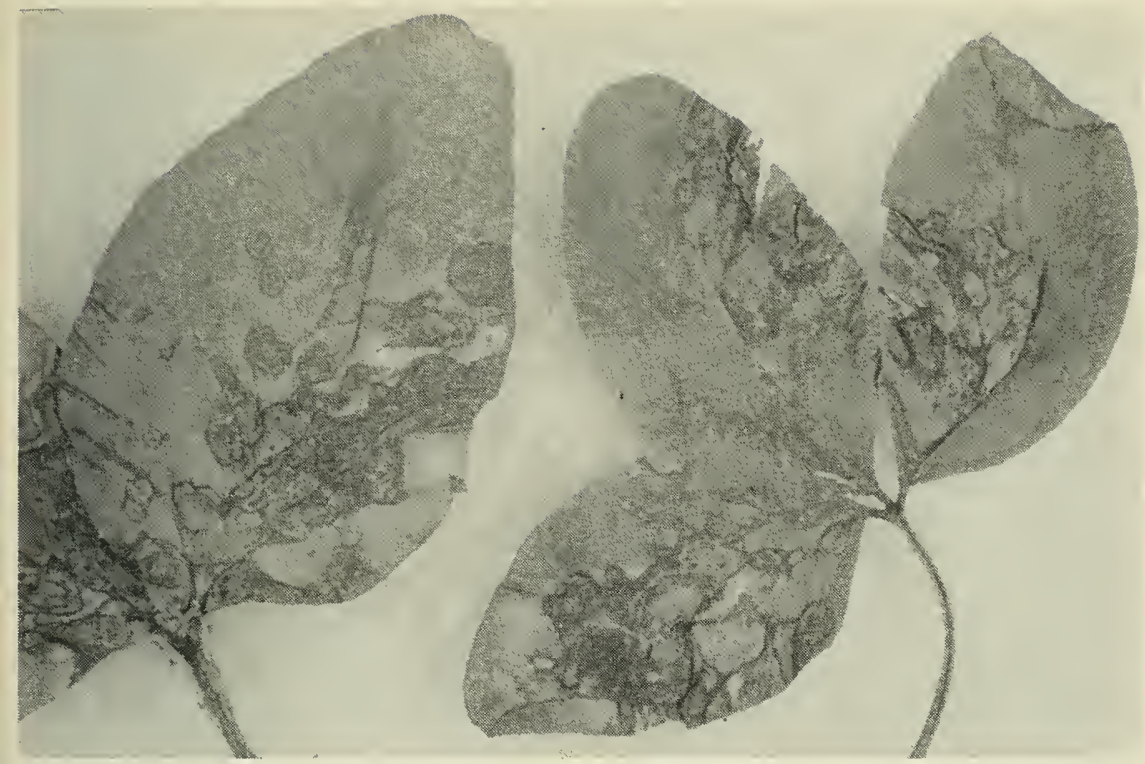

FIGURE 1. Leaf spots on red clover showing the characteristic zonate lesions.

Smith's original report indicated that only leaves were susceptible. Zonate lesions often appear on infected stems (Figure 4). Stem lesions may occur just below the flower head, and usually result in a bending of the stem (Figure 3) which stops floral development. Aerial mycelium may extend upward along the stem in a web-like growth from the crown to the flower head (Figure 2).

Invasion of the floral parts by the mycelium is the same as that described for the leaves. That is, as the initial lesions continue to expand, aerial mycelium radiates outward from the spots and may establish new lesions wherever it comes in contact with the host tissue. Often, the flower head may be covered with a veil of dark mycelium. Infected flower heads may be noticeably reduced in size. The amount of damage caused by the fungus is greatly influenced by the stage of development of the flower parts at the time of infection. As noted previously (6), if the flower head is in the pre-bloom to full-bloom stage, the fungus may invade and kill all parts, including the ovaries, so that no seed is produced. If the parts are attacked after the seed coat has started to harden, some viable seeds may survive. The more mature the seed at the time the flower head is invaded by the fungus, the greater will be the yield of viable seed from that flower head (Figure 5).

Infected seeds may fail to germinate. Leach and Elliott (9) demonstrated that seedlings arising from infected seed may damp-off. The 




FIGURE 2. Enlarged section of a clover stem showing the large black aerial mycelium of the blackpatch fungus. 


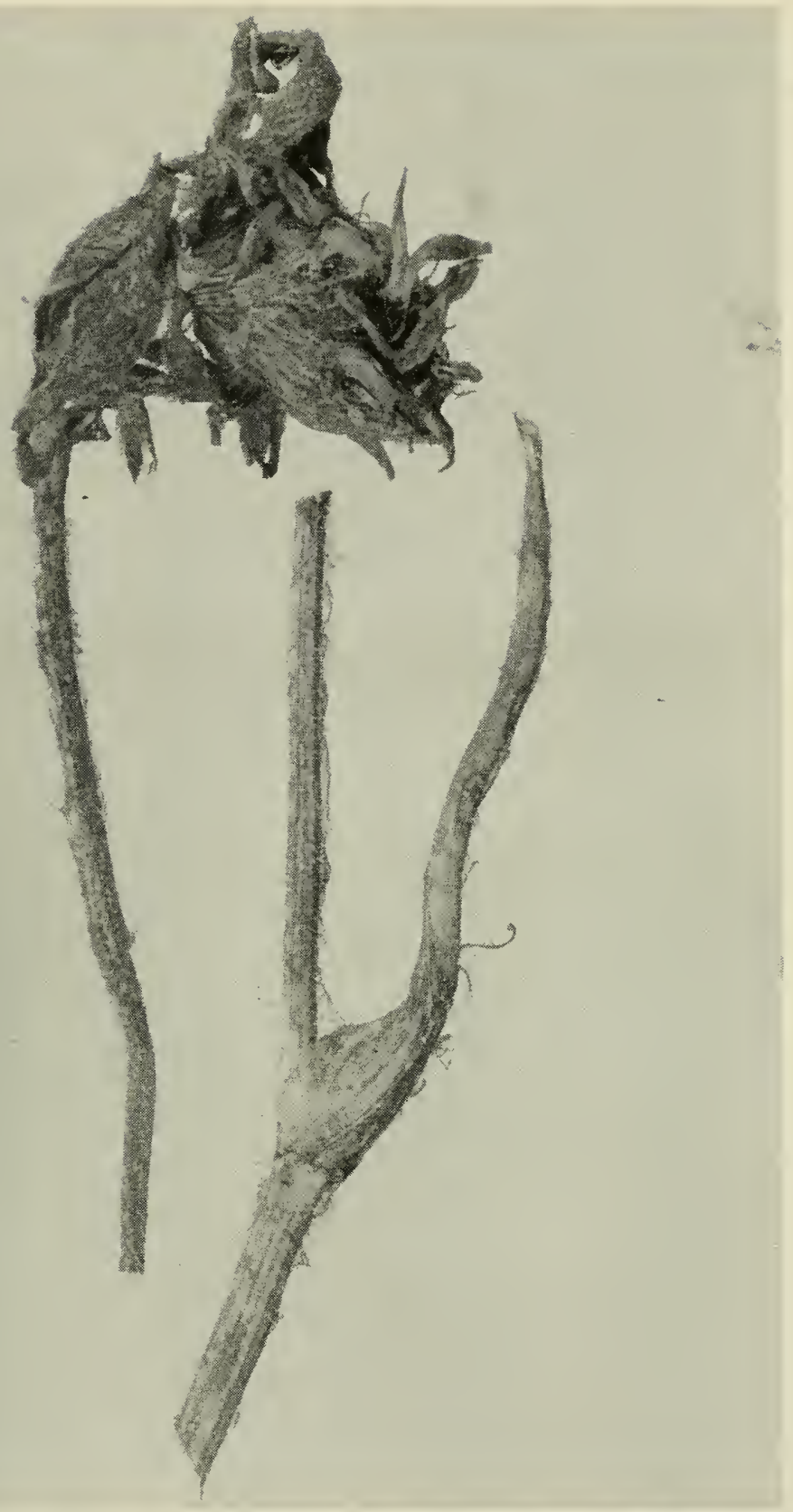

FIGURE 3. A stem section and a flower head overgrown by the blackpatch fungus. Such infected heads may be killed before seeds are formed or before they mature, in which case surviving seeds are likely to be infected by fungus. 




FIGURE 4. Clover stems showing cankers caused by the blackpatch fungus. Stem girdling can result in reduced seed yields even though the fungus does not reach the blossom. 


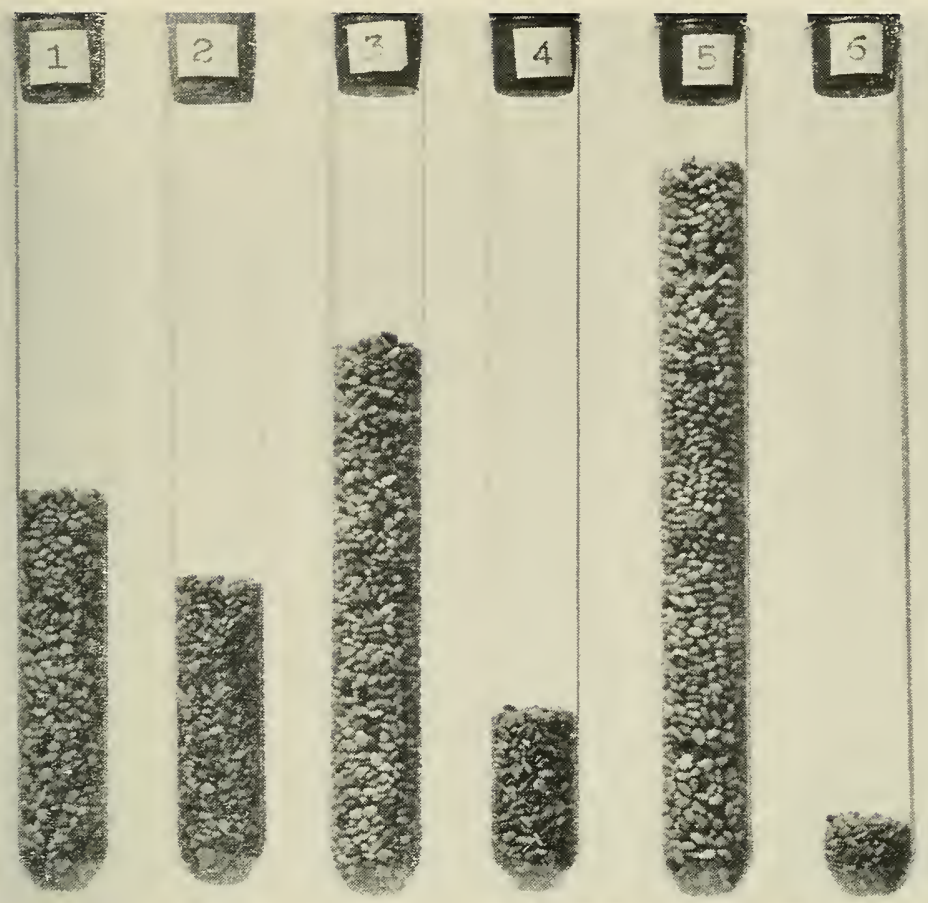

FIGURE 5. Seed yields of three lots of 100 seed heads. (1) and (2) Plump healthy seeds and diseased seeds respectively, taken from 100 heads infected with blackpatch. (3) and (4) Plump and shrivelled seeds respectively from 100 apparently healthy heads from the same field. (5) and (6) Plump and shrivelled seeds from 100 heads from a field apparently free from blackpatch.

symptoms at this stage are similar to those produced by other dampingoff organisms, except that one can often see the dark mycelium on the surface of the infected area (Figure 11, page 21).

Infected seed have shown several different characteristics (9). Seeds infected while they were still immature appear reddish brown and badly shriveled at maturity. Frequently traces of the coarse mycelium of the fungus can be recognized immediately under the seed coat. Seeds in advanced stages of maturity may show degrees of shriveling and discoloration (Figure 10, page 20), but most are of normal shape and color. Some are plump and apparently uninjured except that the coarse black mycelium can be seen radiating out over the surface of the seed from a central invasion point, usually at or near the hilum (Figure 10).

The symptoms of this disease are very obvious upon close examination; nevertheless, farmers often confuse the brown dead plant parts with normal, but early, ripening of the clover. 


\section{Idenity of the Pathogen}

The blackpatch organism was first briefly described (2) as a sterile fungus with large dark brown septate hyphae.

Smith (11) states, "In culture, the mycelium is hyaline when young but soon becomes dark green and finally dark brown or black with age. It is composed of large, branching, septate filaments filled with granular protoplasm but with numerous vacuoles in the older portions. Cells of the larger filaments average about $16 \mu$ in width, although many of them are short and round, having a diameter of $28 \mu$ to $30 \mu$. In shape, these short cells appear much like chlamydospores, but their walls are not thickened and the cell contents do not appear different from those of other cells of the mycelium. In some instances, the fungus produces numerous clusters of short cells in the media, which resemble conidia in grape-like clusters." He further commented that the clusters of the short cells resemble young sclerotia, but since they remained microscopic in size, he did not designate them as true sclerotia.

It is believed that, except for Smith's observations, there are no suggestions in the literature as to the nature of these cells. However, unpublished data collected by Tenney (8) indicated that on glucoseasparagine-agar medium, these cells sometimes develop into sclerotial bodies as much as $2 \mathrm{~mm}$. in diameter.

\section{Sclerotia Studies}

Since the production of sclerotia is a characteristic of prime importance in the classification of the blackpatch fungus, the conditions under which these sclerotia develop were investigated in some detail (8). Various nitrogen and carbon sources were substituted for the glucose and asparagine contained in the basal agar medium on which the sclerotia were first noted. This medium, except for the added agar, contained the same materials as a basal medium previously described by Lilly and Barnett (10).

First, various nitrogen sources were tested with the glucose carbon source in the medium remaining constant. The concentration of the nitrogen in each of the compounds rvas substituted in an amount equivilent to that of the asparagine. The average number of sclerotia from cultures (five replications) on the various nitrogen sources were as follows: asparagine (Difco), 364; DL-beta-phenylalanine, 92; peptone (Difco), 381; potassium nitrate, 121; casein hydrolysate, 3; urea, 0; casamino acid, 0; ammonium sulfate, I; ammonium tartrate, 0; ammonium nitrate, 0 . Sclerotia were not produced when the medium did not contain a source of nitrogen. 
The average number of sclerotia per culture increased as the nitrogen (asparagine, Difco) content of the medium was increased from 0.001 per cent to 0.05 per cent. At greater concentrations the production of sclerotia slowly declined. The average number of sclerotia in five replications at the various asparagine concentrations were as follows: 0.0 per cent, 0 sclerotia; 0.001 per cent, 4.3 sclerotia; 0.01 per cent, 377 sclerotia; 0.025 per cent, 309 sclerotia; 0.05 per cent, 587 sclerotia; 0.1 per cent, 551 sclerotia; 0.2 per cent, 496 sclerotia; 0.4 per cent, 409 sclerotia.

The nature of the carbon source also influenced the sclerotial development of the fungus in culture. The various sugars tested were added to the medium in amounts so that the quantity of carbon in each was equivalent to that of glucose. The average number of sclerotia from five replicated cultures containing each sugar was: D-glucose, 346; D-mannose, 331; D-fructose, 352; D-galactose, 34; D-xylose, 46; maltose, 367; lactose, 74; sucrose, 358. An average of 17 sclerotia were counted when no carbon source was included in the medium.

The poor, or slow utilization of D-galactose and D-xylose may be ascribed to the molecular configuration and structure of these sugars, the importance of which in relation to growth was pointed out by Lilly and Barnett (10). Since lactose has never been reported as occurring in plants, it is possible that the fungus lacks the enzymes necessary for rapid utilization of this sugar.

The concentration of the glucose in the medium also had a marked influence on the number of sclerotia formed. The average number of sclerotia from five replications of each sugar concentration was: 0.0 per cent, 27 sclerotia; 0.1 per cent, 412 sclerotia; 0.2 per cent, 530 sclerotia; 0.35 per cent, 430 sclerotia; 0.75 per cent, 484 sclerotia; 1.0 per cent, 439 sclerotia; 2.0 per cent, 262 sclerotia. A concentration of 0.2 per cent glucose appeared to be the optimum for sclerotia production.

The optimum temperatures for sclerotial formation and mycelial growth were approximately the same. The average number (5 replicalions) of sclerotia produced on the glucose asparagine agar medium when cultures were held at various temperatures was as follows: $10^{\circ} \mathrm{C}, 1$ sclerotium; $15^{\circ} \mathrm{C}$, 31 sclerotia; $20^{\circ} \mathrm{C}, 62$ sclerotia; $25^{\circ} \mathrm{C}, 243$ sclerotia: $29.5^{\circ} \mathrm{C}, 261$ sclerotia; $33^{\circ} \mathrm{C}, 107$ sclerotia; $37^{\circ} \mathrm{C}, 0$ sclerotia.

Initial $\mathrm{pH}$ values of the medium ranging from 5.9 to 7.5 favored the formation of sclerotia. On media having initial $\mathrm{pH}$ values of 8.5 and 9.2 , the colony diameter was reduced, sclerotia coalesced, and the hypae were densely matted. Allington (1) described a similar condition of the hyphae of Rhizoctonia solani Kuhn on modified Czapeks medium which had an initial $\mathrm{pH}$ of 8.0, but sclerotial hyphae were not observed. 


\section{General Description of the Pathogen}

The blackpatch fungus has never been observed to produce spores; it is undoubtedly for this reason that it has not been classified and named. Present knowleckge of the organism and of its ability to form prominent sclerotia, seem to justify placing the fungus in the genus Rhizoctonia. Although DeCandolle (3) originally described the genus, the International Code of Nomenclature considers that the first taxonomically valid description of the genus Rhizoctonia is given in Fries Systema Mycologicum ( 7$)$. The following is a translation of Fries' Latin description.

\section{Rhizoctonia DC. ex Fr.}

Varying in shape and size (sclerotia), growing together, cartilaginous to fleshy, of uniform texture within; cortex very thin, membranaceous, inseparable, persisting; rootlike cottony threads growing out in fasicles from the comers, joining several individuals. No fruiting structures evident.

Subterranean fungi, developing freely, growing on roots of living plants and killing them. Occurring in summer or autumn, rather persistent, highly injurious. Closely approaching subterranean sclerotia.

The main characters which indicate that the blackpatch fungus should be included in this genus are: (1) the lack of any type of sporulation, (2) the production of sclerotia in culture, and (3) the frequent constrictions of the hyphal branches at their point of origin (Figure 6).

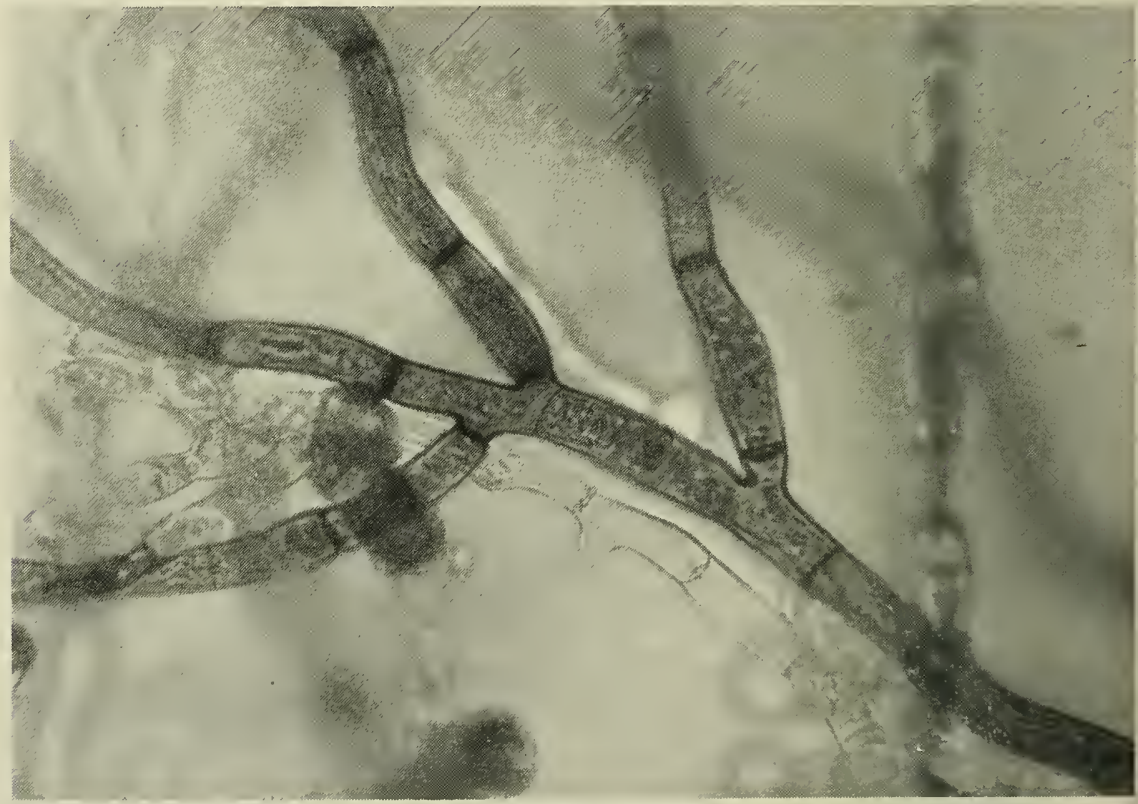

FIGURE 6. Vegetative hyphae of Rhizoctonia leguminicola, showing the constriction at and the septum near the point of union of the young hyphae and the parent branch. (Approx. 250x.) 
Fries' description does not mention the characteristic constriction of the hyphal branches at their point of origin and the occurrence of a septum close to the point of branching, found in at least some species of the genus. Apparently these characteristics have been accepted as typical of the group in more recent years. This is indicated in the general description of the genus given by Duggar and Stewart (4).

Early descriptions of the genus specify the roots of plants as the habitat of these fungi. The blackpatch fungus is not commonly associated with the roots of the host plants, but this is not believed to be a particularly important feature.

In pure culture, the young hyphae are hyaline and contain clense protoplasm, especially toward the tips. As the culture ages, the hyphae reach a diameter of 15 to $16 \mu$, the contents become more granular, and large vacuoles appear. The walls become thick, rigid, and more deeply pigmented. Anastomosing of hyphae is very common in the younger filaments. Branches develop either singly or dicotomously; in the first instance they grow out as acute angles from the parent hyphae, usually arising near the cross walls. A constriction is often apparent at the point of origin and a septum is commonly formed a few microns beyond, as in Figure 6.

When Petri dishes containing water agar were flooded with a suspension of mycelial fragments in sterile distilled water, renewed growth from these mycelial fragments was seen to occur by emergence of a germ tube through a septum. Wherever the end cell of a fragment was broken and devoid of protoplasm, the germ tube developed from the next living cell. It would then pass through the empty broken cell and outward into the medium. Duggar and Stewart (4) described this method of renewing growth for fragments of hyphal tufts of Rhizoctonia solani Kuhn.

Short, rounded cells often occur in the mycelial strands. They are not easily mistaken for spores since they are joined on both ends by typical elongated cells, and they occur in the substratum as well as in acrial mycelium. Duggar and Stewart (4) have also described similar structures in the mycelium of infection cushions of Rhizoctonia crocorum (Pers.) DC. Larger, rounded intercalary cells also occur. These may reach a maximum cliameter of $48 \mu$. The present observations indicatc that these are not chlamydospores. This was also the conclusion reached by Smith (11).

In culture, sclerotia originate at the tips of young hyphae by profuse branching and anastomosing (Figure 7). Mature sclerotia are round to irregular in shape with rough glossy black surfaces, as illustrated in Figure 8. They vary in size from 1 to $2.5 \mathrm{~mm}$. in diameter. However, 

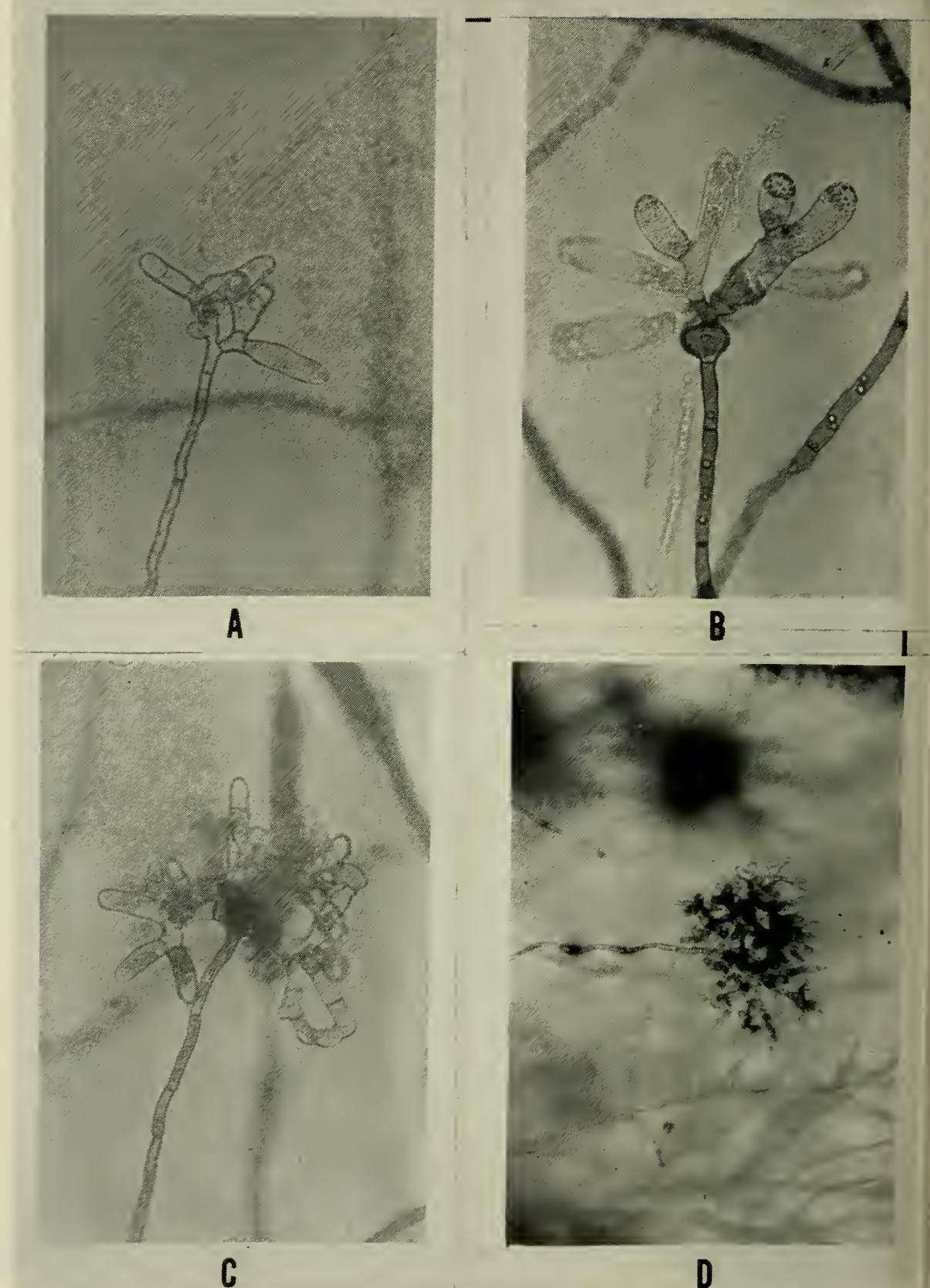

FIGURE 7. Progressive stages of development of sclerotia of Rhizoctonia leguminicola. Note the anastomosing sclerotial hyphae in C. (Approx. mag. A, $100 X ; B, 125 X ; C, 125 X ; D, 50 X$. 

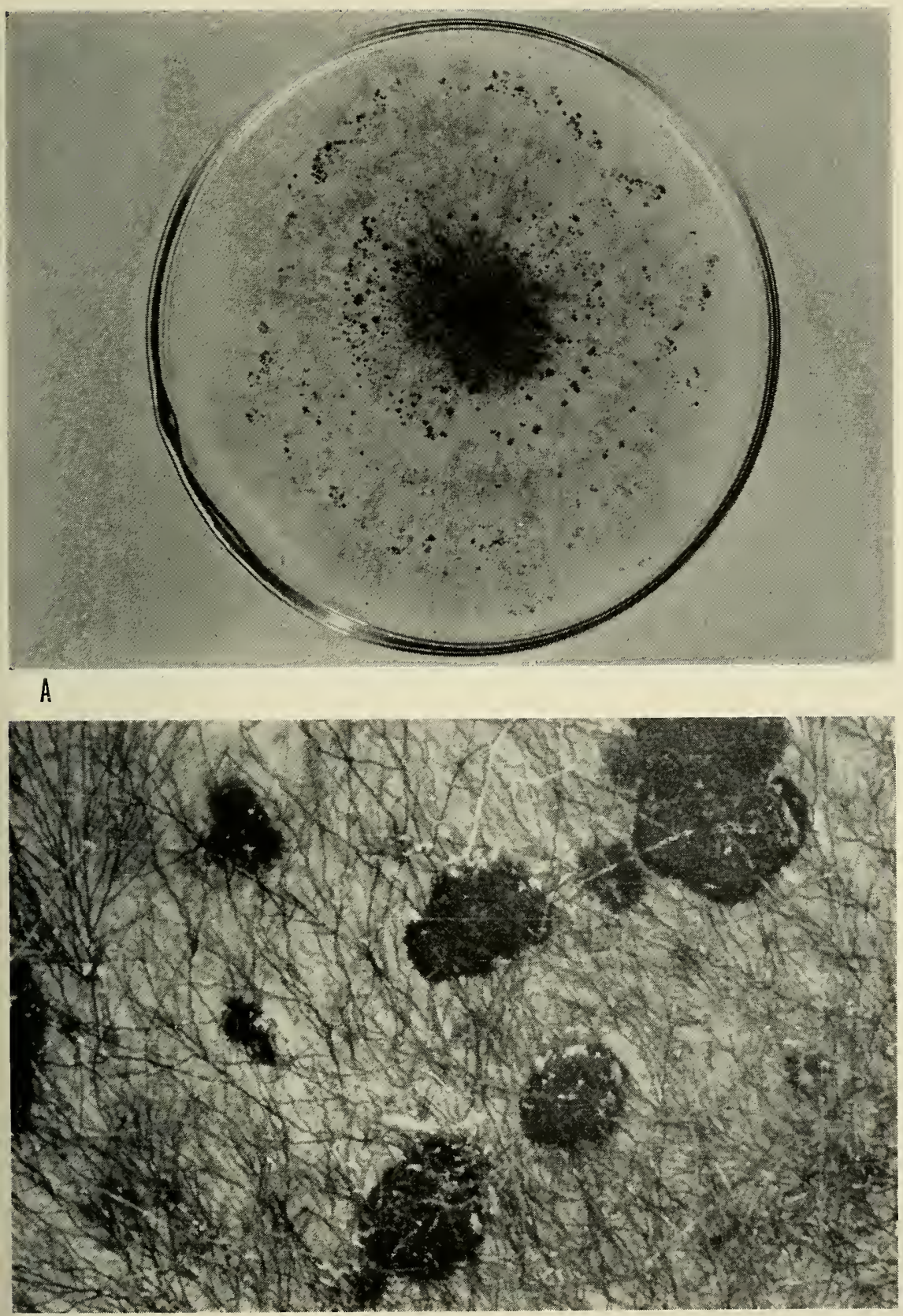

B

FIGURE 8. A. Petri dish culture of Rhizoctonia leguminicola showing numerous sclerotia. B. Mature sclerotia of Rhizoctonia leguminicola. (Approx. 15X.) 


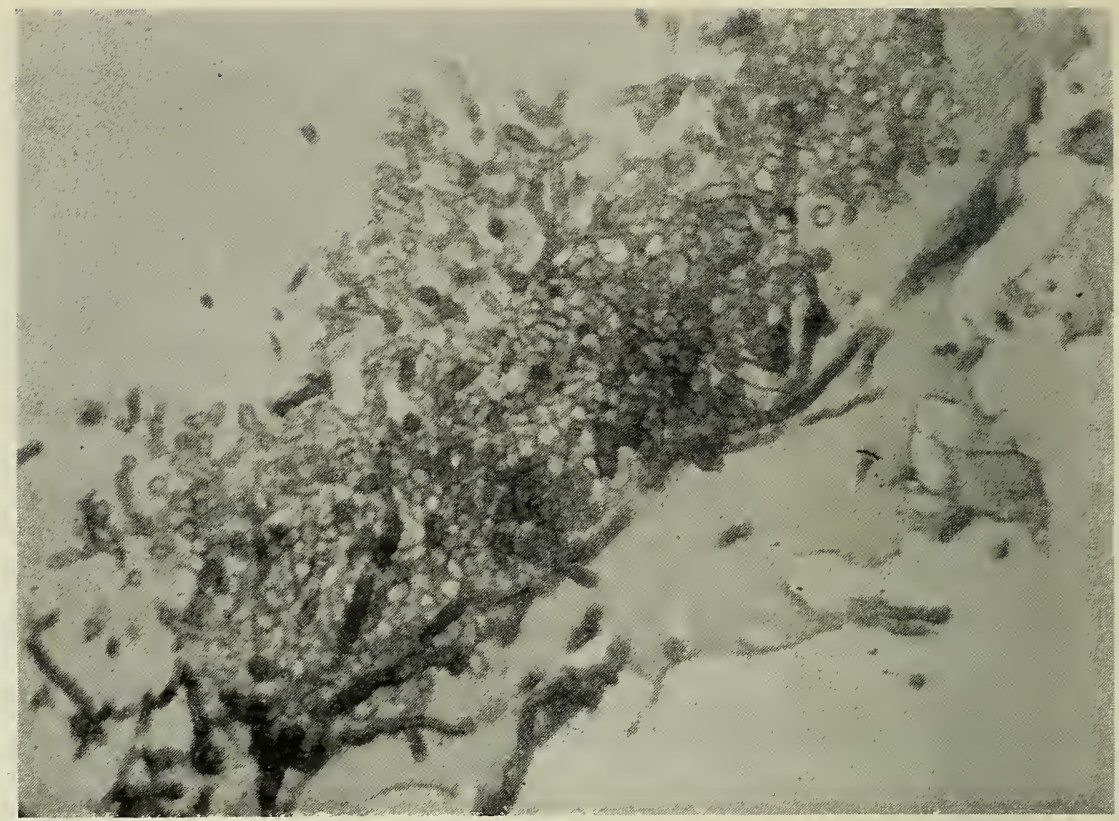

FIGURE 9. A section through a sclerotium of Rhizoctonia leguminicola. (Approx. 75 X.)

in some cases they may coalesce to form large irregular masses. Sections of the sclerotia show them to be fairly homogenous in color and structure (Figure 9). Sclerotia have never been observed in nature.

\section{Technical Description of the Blackpatch Fungus*}

Rhizoctonia leguminicola sp. nov.

Garet sporis. Mycelium septatum vulgo dichotoinis ramis, hyalinum inition, atroviride, fuscum, seu atrum ubi matuıum; ramis hyphalicis saepe ad punctum originis constrictis, et pauca micra ultra septatis; protoplasmate spisso, granulato primo auctu, partibus maturis vacuolatissimis; cellulis maturis 15-16 micra latitudinem, 15-240 micra longitudinem. Cellulae breves, globosäc, intercalariae, 28-48 micra dianetrum, saepe in cultura propagatis inveniuntur. Sclerotia atra textura laxa usque ad solida, eiusdem generis forma et colore, 1-2.5 millimetra cliametrum, ad apices hypharum ramis iteratis et anastomosatis in quibusdam culturis nascuntur. Sclerotia in statu naturali non reperta sunt.

Habita Parasitica: in Trifolium pratense et non nullis ceteris leguminbus.

*The authors wish to express their appreciation to Edith K. Cash and J. A. Stevenson, Plant Disease Epidemics and Identification Section, U.S.D.A. for the aid that they gave with the Latin descriptions. 
Spores lacking. Mycelium septate, usually dicotomously branched, hyaline when young, dark green, brown or black with age; hyphal branches often constricted at point of origin with septum formed a few microns beyond. Dense granular protoplasm in young growth, older portions highly vacuolate; mature cells 15 to 16 microns wide by 15 to 240 microns long. Short, round intercalary cells 28 to 48 microns in diameter, frequently occur in culture. Numerous, black, loose to compact sclerotia, homogenous in structure and color, 1.0 to 2.5 millimeters in diameter, arise at apices of hyphae by repeated branching and anastomosing on some media. Sclerotia have not been observed in nature.

Parasitic on red clover and several other legumes.

Known Geographic Range: Scattered throughout eastern and midwestern areas of the United States.

Type material has been deposited at the Mycological Herbarium at West Virginia University, Morgantown, West Virginia, and in the U.S.D.A. Mycological Herbarium at Beltsville, Maryland.

\section{Pathogenicity}

R. leguminicola is pathogenic on many leguminous hosts. Smith (11) inoculated 12 plant species and found red clover (Trifolium pratense L.), white clover ( $T$. repens $\mathrm{L}$.), ladino clover (T. repens giganteum Lagr.-Foss), crinson clover ( $T$. incarnatum L.), alsike clover ( $T$. hybridum L.), white sweetclover (Melilotus alba Desr.), yellow sweetclover (M. officinalis [L.] Lam.), sour clover (M. indica [L.] All.), and alfalfa (Medicago sativa L.) to be susceptible. Broad bean (Vicia faba L.), kidney bean (Phaseolus vulgaris L.), and cabbage (Brassica olenacea L.) were immune.

Weimer (14) added to the lists of hosts, soybean (Glycine max [L.] Merr.), corpea (Vigna sinensis [Torner] Savi.), kudzu (Pueraria thumbergiana [Sieb. \& Zucc.] Benth.) and blue lupine (Lupinus angustifolius L.).

The present writers have observed the disease in West Virginia on black medick (Medicago lupulina L.) and Korean lespedeza (Lespedeza stipulacea Maxim.) as rell as on red clover, white clover, alsike clover, and alfalfa. Greenhouse inoculations with an isolate from red clover caused heavy infection on an unnained variety of bush bean (Phaseolus mulgaris var. humilis) but not on garden pea (Pisum sativum L.) or birdsloot trefoil (Lotus comiculatus L.). It was pointed out (6) that in this region the disease usually appears on other species only when they are adjacent to infected red clover plants.

Wells (15) recently reported the susceptibility of big trefoil (Lotus uliginosus Schkuhr.). Tenney (12) inoculated several non-leguminous 

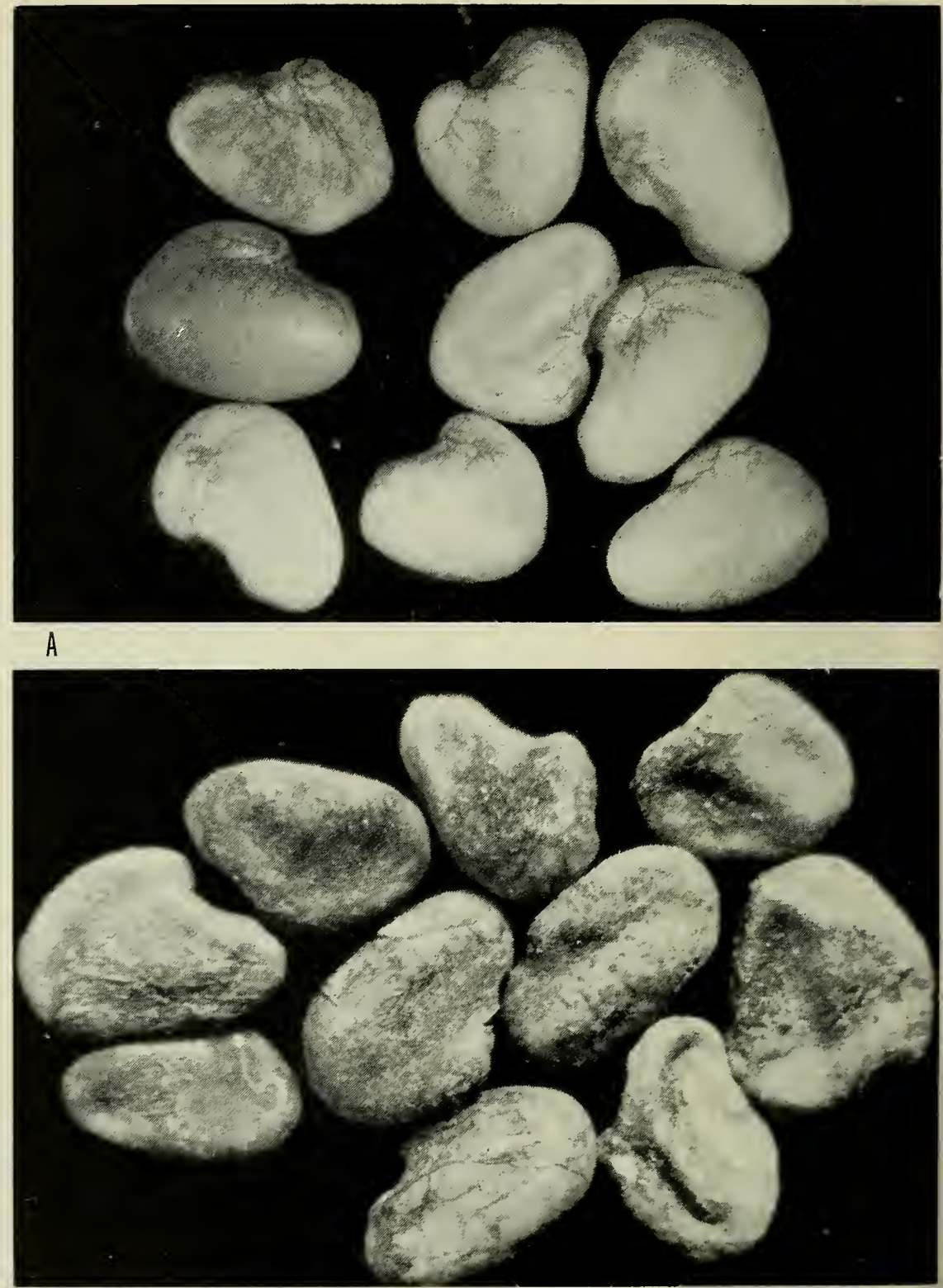

$B$

FIGURE 10. A. Red clover seeds lightly infected by R. leguminicola. Note the large black mycelium radiating from the hilum over the surface of the seeds. Such seeds usually are slightly shrivelled but nearly always viable. B. Ten severely infected red clover seeds showing the mycelium that has penetrated and grown under the seed coat. Such seeds are shrivelled, discolored, and often dead, but some may still be viable. 




FIGURE 11. Germinating red clover seedling arising from seed such as those in Figure 10. Note the black mycelium of blackpatch fungus that has grown out from the seed coat and is infecting one of the cotyledons and the hypocotyl. 
plants and found that although the mycelium sometimes spread over their surfaces, no infection occurred.

\section{Effect of Drying on $R$. leguminicola}

It was noted that the mycelium of $R$. leguminicola used in these studies was more resistant to desiccation than had been observed and reported by Smith (II) who stated "when leaves are inoculated and placed in an atmosphere of high humidity until the fungus has become established within the leaf tissue and are then placed in an atmosphere of low humidity, aerial mycelium is killed and the advance of the fungus is limited to growth within the leaf tissue until a high humidity again permits growth of aerial mycclium." Smith also reported that the fungus is killed by drying in pieces of agar inoculum at a relative humidity of 60 to 70 per cent.

In the present study, it was found that mycelium taken from the surface of red clover stems, which had been stored at room temperature for one year, was still viable when transferred to water agar.

To further study this resistance to drying, mycelium of $R$. legumincola grown in a liquid medium was washed, dried, and finally placed in desiccators containing Drierite. Relative humidity in the desiccators approached 0 per cent; temperature was maintained at $20^{\circ} \mathrm{C}$. Periodic tests showed that the dried mycelium remained viable for six months; no growth was produced at the end of seven months.

Although the fungus is favored by high humidity, its ability to withstand considerable desiccation suggests that dew may supply sufficient moisture for the development of the disease, even in arid regions.

\section{Overwintering of the Fungus}

The most obvious means of overwintering for $R$. leguminicola is in or on the seed which is harvested and stored during the winter period. Such seed when planted in the spring carry the pathogen with it. This may result in damping-off of some of the seedlings even before the plants are established.

A number of observations and experiments inclicate that the mycelium of $R$. leguminicola is sufficiently resistant to cold and to various other conditions to survive the winter in this region. For example, blackpatch mycelium stored at $-20^{\circ}$ C. lor 30 clays was viable and caused infection. However, the fungus was not viable after 60 days exposure to these conditions.

Even though most attempts to locate the viable mycelium which overwinters have failed, it is evident that such mycelium does carry 
through the winter. Possibly only smail amounts live over, as is indicated by the difficulty in finding viable material during winter months. The fungus can easily be found soon after the first warm weather of spring.

Fifteen red clover plants (including the root systems), collected in March from a field which had been infected with blackpatch the previous year, were washed to remove any soil and placed in a humidity chamber. Only very slight new growth had developed at this time. After five days, $R$. leguminicola mycelium was observed growing from the crown area of one of the plants. It could not be determined whether this mycelium originated from living or dead tissuc, but it indicated that the fungus had overwintered in the crown area.

Another possible means is for the fungus to be carried overwinter in or on naturally dropped seed from infected plants which had blossomed late in the season. This possibility is supported by the observation that early spring planted seeds which carry the fungus may dampoff on germination. This is particularly evident at points where excessively large amounts of the seed are dropped on the surface of the soil by the drill.

Since large, compact sclerotia, like those formed in culture, have not been found in nature, this means of overwintering is discounted.

\section{Dissemination of the Pathogen}

\section{Seed Transmission}

The exchange of seed between growers in an area, such as the seed producing region in West Virginia, provides a very effective means of dissemination, even though it is an artificial method. This undoubtedly serves also to carry the pathogen long distances.

Since the fungus has no known means of local spread from the original infection centers except by mycelial growth, the frequent occurrence of isolated spots in the upper parts of the plants has been a problem. These spots have no visible mycelial connection with the other infections which commonly occur at the base of the plant. It has been suggested (6) that the first-formed leaves are probably infected near the ground at the time of origin of the new stem, and the mycelium is thus carried upward with the elongation of the stem.

\section{Control}

Over a period of years, a number of attempts have becu made to find some practical means of controlling blackpatch. None of these has met with marked success, but it is still believed that practical control may be achieved under certain conditions. None of the different control measures tested should as yet be definitely discarded. These inchude (1) 
the application of foliage fungicides to the seed crop before the flowering period, (2) eradication of the fungus by a ground spray at about the time of renewed growth in the spring and again following removal of the hay crop, and (3) seed treatment. A search has also been made for red clover plants showing resistance to the fungus.

Because the disease has not been a major problem in red clover seed production except during wet seasons, it was believed that damage to the seed crop could be most effectively stopped by using the proper fungicide on the foliage just before the flowering period. Large-scale application of a fungicide at that time involves the use of heavy spray equipment in the field and results in some loss of seed due to crushing of the plants. No successful treatments have been completed under field conditions. A few fungicides which control the disease under greenhouse conditions may yet prove to be of value when further tested in the field.

Attempts to eradicate the fungus from diseased fields have not been successful. Wetting ground sprays of various fungicides, applied when new growth of the plants starts in the spring and also following removal of the hay crop have so far not been effective. This group of sprays included a number of the eradicant-type fungicides.

Under greenhouse conditions optimum for disease development, the same group of fungicides applied to red clover plants which were later inoculated with $R$. leguminicola showed that some of them offered protection to the plants. Bioquin I gave the best control, Orthocide 406 appeared to be the second best, while Parzate liquid fungicide ranked a close third.

Field tests made by Tenney (12) utilizing one-quarter-acre plots indicated that Tersan would not reduce the amount of blackpatch present. The fungicide was applied to the foliage in dust form in three applications between the first cutting and harvest of the seed crop. Seed yields from treated plots were essentially the same as those from the check plots.

Tenney (12) also reported that Arasan seed treatment gave partial early control of blackpatch, but its over-all effectiveness was discounted. Blackpatch still appeared in abundance, probably due to contamination of the field from other sources, such as infected volunteer plants and debris.

It has been found by earlier work (9) that treatment of infected seed with Arasan ( 1 part to 100 parts of seed weight) gave considerable control of the damping-off phase of the disease under greenhouse conditions. Although seed treatment may give only limited and temporary control of the organism in fields in the region where blackpatch is 
commonly found, it is undoubtedly of considerable value as a means of increasing the original stand due to reduction of damping-off.

It is assumed that red clover plants resistant to $R$. leguminicola are most likely to be found in populations growing in the area where the disease is severe. On this basis, an attempt was made to find such plants. Large numbers of plants were grown from seed collected from infected fields in the eastern part of West Virginia. Repeated inoculations of these plants in the greenhouse showed that with optimum conditions for fungus growth, all plants of the large population tested were susceptible. The red clover plants were 2 to 6 months of age when inoculated. The discovery of plants resistant to this disease appears to be the only really practical means of controlling the fungus.

\section{Literature Cited}

1. Allington, W. B., "Sclerotial Formation in Rhizoctonia solani as Affected by Nutritional and Other Factors." Pliytopath., 26:831-814, (1936).

2. Anonymous. Blackpatch of Clozer. Ky. Agr. Exp. Sta. Rpt. 46:30, 1933.

3. Candolle, A. P. de "Nemoire sur les rhizoctones, nouveau genre de champignons qui attaque les racines, des plantes et en particulier celle de la luzerne cultivec." Mem. du Mus. d'Hist. Nat. 2:209-216, (1815).

4. Duggar, B. M. and Stewart, F. C., The Sterile Fungus Rhizoctonia as a Cause of Plant Diseases in America. Cornell Univ. Agr. Exp. Sta. Bull. 186:1-30, 1901.

5. Elliott, Edward S. and Leach, J. G., "Blackpatch' as a Limiting Factor in Redclover Seed Production in West Virginia." (Abstr.) Phytopath., 40:7, (1950).

6. - - . . Diseases, Insects and Other Factors in Relation to Red Clover Failure in West Virginia. W. Va. Univ. Agr. Exp. Sta. Bull. 351T: 1-65. 1952.

7. Fries, E., Systema mycologicum 2:265-266, (1823).

8. Gough, Francis J., Rhizoclonia leguminicola sp. nov., The Cause of Blackpatch of Red Clover and Other Legumes. M.S. Thesis, West Virginia University. 1954.

9. Leach, J. G. and Elliott, Edward S., "The Blackpatch Disease of Red Clover and Other Legumes in West Virginia." Phytopath., 41:1041-1049, (1951).

10. Lilly, V. G., and Barnett, H. L., The Utilization of Sugars by Fungi. W. Va. Univ. Agr. Exp. Sta. Bull. 362T:1-58. 1953.

11. Smith, O. F., "A Leafspot Disease of Red and White Clovers." Jour. Agr. Res. $54: 591-599$, (1937).

12. Tenney, W. R., The Blackpatch Disease of Red Clover. M.S. Thesis, West Virginia University. 1952.

13. - - "The Nature of Seed Transmission in Blackpatch of Red Clover." Proc. West Virginia Acad. Sci., 24:68-71, (1952).

14. Weimer, J. L., "Blackpatch of Soybeans and Other Legumes." Phytopath., 40:782$784,(1950)$.

15. Wells, Homer D., "Diseases of Big Trefoil in Georgia." U.S. Dept. Agr., Pl. Dis. Reptr., 37:521. (1953). 


